\title{
Distinguishing duodenal duplication cyst from choledochocele: A case report
}

\author{
Ongoly Okiemy ${ }^{1}$, Helene Meunier ${ }^{2}$, Allan M. Goldstein*3 \\ ${ }^{1}$ Department of Pediatric Surgery, Maison Blanche Hospital, Reims-Champagne-Ardennes University, Reims, France \\ ${ }^{2}$ Department of Pediatrics, Maison Blanche Hospital, Reims-Champagne-Ardennes University, Reims, France \\ ${ }^{3}$ Department of Pediatric Surgery, Massachusetts General Hospital, Harvard Medical School, Boston, Massachusetts, United \\ States
}

Received: June 13, 2019

Accepted: July 12, 2019

Online Published: August 2, 2019

DOI: $10.5430 /$ css.v5n1p34

URL: https://doi.org/10.5430/css.v5n1p34

\begin{abstract}
Duodenal duplication cysts (DDC) are a rare type of enteric duplication. We describe the clinical presentation and laparoscopic management of a 7-year-old boy with a periampullary DDC. We also discuss the embryologic and imaging features that distinguish DDC from choledococele (CC). Careful consideration of the anatomic relationships between the ampulla, common bile duct, and duplication cyst are essential to avoid intraoperative bile duct injury.
\end{abstract}

Key Words: Duodenal duplication cyst, Choledochocele, Laparoscopic, Surgery, Enteric duplication

\section{INTRODUCTION}

Enteric duplication cysts are rare congenital anomalies, occurring in 1 in 4,500 births. ${ }^{[1]}$ They can be located anywhere from oropharynx to anus, but mainly occur in the ileum. ${ }^{[2]}$ These cysts are located on the mesenteric side of the bowel and share a common blood supply with the adjacent bowel. ${ }^{[2,3]}$ Most (70\%) are identified before 2 years of age. ${ }^{[1]}$ Midgut duplications are often associated with obstructive symptoms, including feeding intolerance, early satiety, pain, nausea, and emesis. ${ }^{[1]}$ Duodenal duplication cysts (DDC) are rare and represent less than 5\% of all enteric duplications. ${ }^{[4]}$ The clinical presentation of duodenal duplication can be similar to type III choledochal cyst, also called choledochocele (CC), and distinguishing between these two diagnoses can be difficult.

Here we report the case of a 7-year-old boy with a peri- ampullary DDC managed laparoscopically and we discuss the features that distinguish this lesion from a CC.

\section{CASE PRESEnTAtion}

A 7-year-old male presented to pediatric surgery with a history of recurrent epigastric abdominal pain for 5 months for which he was hospitalized three times. He did not experience any fever, nausea, or vomiting. Abdominal ultrasound was obtained and identified a $4.2 \mathrm{~cm} \times 2.0 \mathrm{~cm} \times 3.5 \mathrm{~cm}$ thick-walled complex fluid collection containing debris and located just below the liver and adjacent to the gallbladder and kidney. A follow-up ultrasound suggested that the lesion was exophytic to the inferior margin of the right lobe of the liver. An abdominal CT scan was then performed and showed a $3 \mathrm{~cm}$ thick-walled cyst adjacent to the duodenum (see Figure 1A). Magnetic resonance cholangiopancreatography (MRCP) was performed and demonstrated a $2.1 \mathrm{~cm} \times$

*Correspondence: Allan M. Goldstein; Email: agoldstein@partners.org; Address: Department of Pediatric Surgery, Massachusetts General Hospital, Harvard Medical School, Boston, Massachusetts, United States. 
$3.7 \mathrm{~cm} \times 4.2 \mathrm{~cm}$ fluid-filled and thick-walled cystic structure ure 1B).

directly arising from the second portion of the duodenum,

without communication with the common bile duct (see Fig-
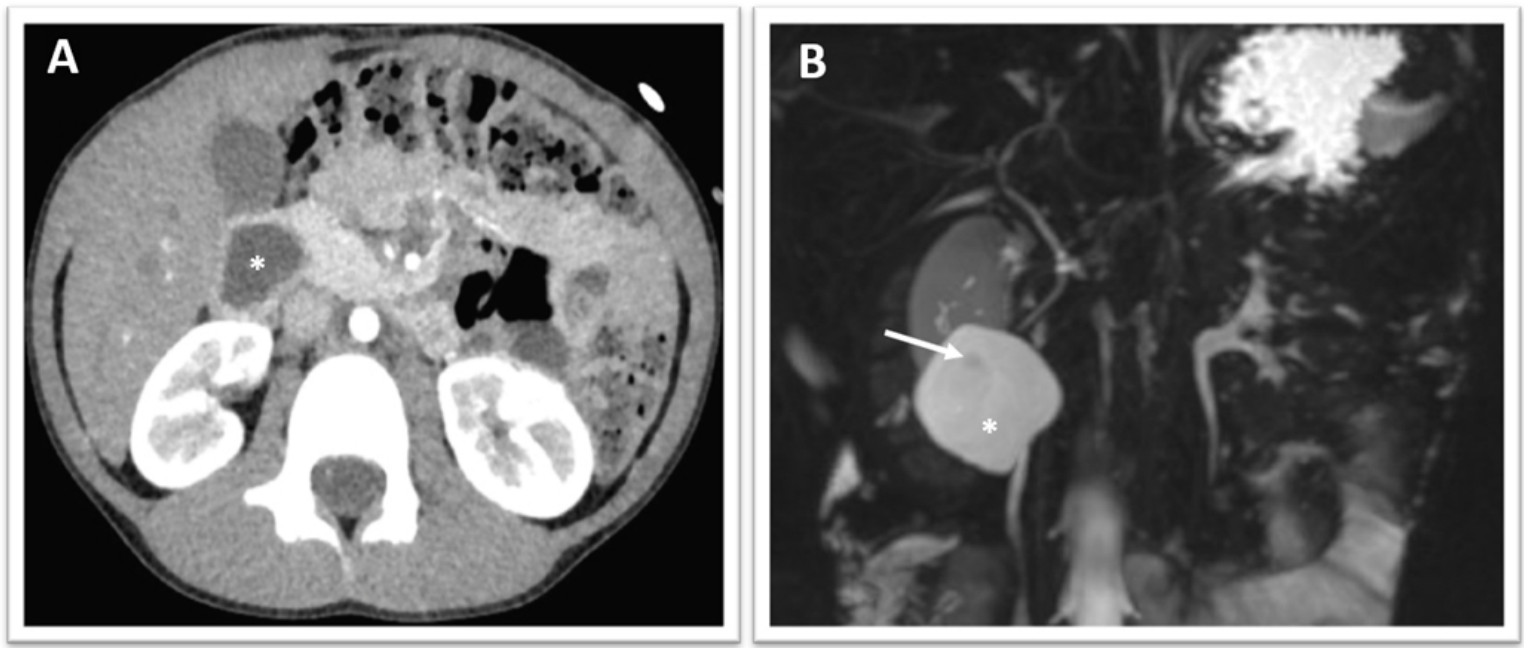

Figure 1. Thick-walled duodenal duplication cyst $\left(^{*}\right)$ on CT scan (A) without communication with the common bile duct on MRCP (B). The ampulla (arrow)

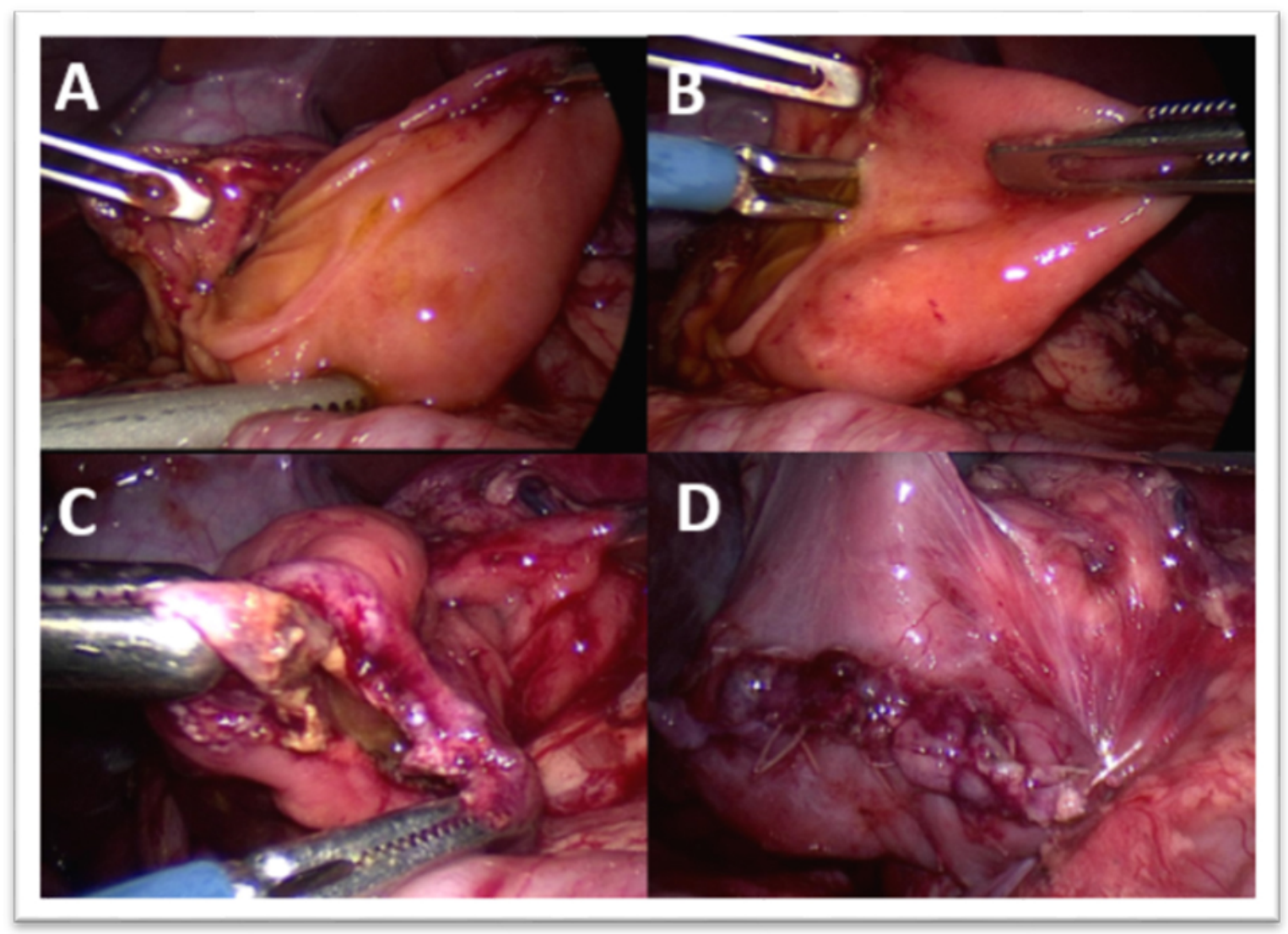

Figure 2. The duodenal duplication cyst (A) has been pulled out through the duodenotomy. A dissector was placed into the ampulla (B), and bile came out. The cyst wall was opened and partially excised (C), and the duodenotomy was then closed transversely (D) 
The patient was brought to the operating room and placed in lithotomy. Laparoscopy was performed using four $5 \mathrm{~mm}$ ports placed at the umbilicus, both sides of the mid-abdomen, and the left upper quadrant. After mobilizing the hepatic flexure using the Ligasure and separating the transverse colon, a Kocher maneuver exposed the duodenum laterally. A transduodenal incision was performed to expose the cyst, which was present within the duodenum (see Figure 2A). Along the lateral side of the mass a small duct like structure stretched up to what appeared to be the ampulla, which could be confirmed by the presence of bile emanating from it when probed with a dissecting instrument (see Figure 2B). The ampulla seemed to be repressed by the mass. The cyst was located on the inner wall of the medial duodenum and therefore displaced the ampulla so that it was located seemingly inside the duodenum and on the cyst wall. The cyst was then opened and the cyst wall partially excised (see Figure 2C). Care was taken not to injure the bile duct or ampulla. The duodenotomy was closed transversely using interrupted 4-0 absorbable suture (see Figure 2D).

The pathology report confirmed that the lesion represented a benign enteric duplication cyst. At 8-weeks follow-up the patient was doing well, without abdominal pain or any gastrointestinal symptoms.

\section{Discussion}

DDCs represent a small fraction of enteric duplication cysts. Sujka et al reported 2 DDCs of 35 enteric duplications in a single-center retrospective study over 10 years, ${ }^{[5]}$ and Guérin reported 7 cases out of 114 enteric duplications in a multicenter study over 15 years. ${ }^{[6]}$

Several approaches have been described to treat enteric duplications, including open and minimally invasive, with or without endoscopy. ${ }^{[5-7]}$ Guérin reported 4 cases successfully treated by laparoscopy, with 3 other cases requiring conversion to open surgery. However, laparoscopic surgery was more often used to unroof $(n=5)$ than to excise $(n=2)$ the cyst. $^{[6]}$ Classically, a transduodenal approach is preferred for DDCs with complete or partial resection, with mucosectomy or marsupialization of any remaining cyst. Partial duodenectomy or pancreaticoduodenectomy have also been reported, ${ }^{[1]}$ as has endoscopic marsupialization. ${ }^{[8,9]}$

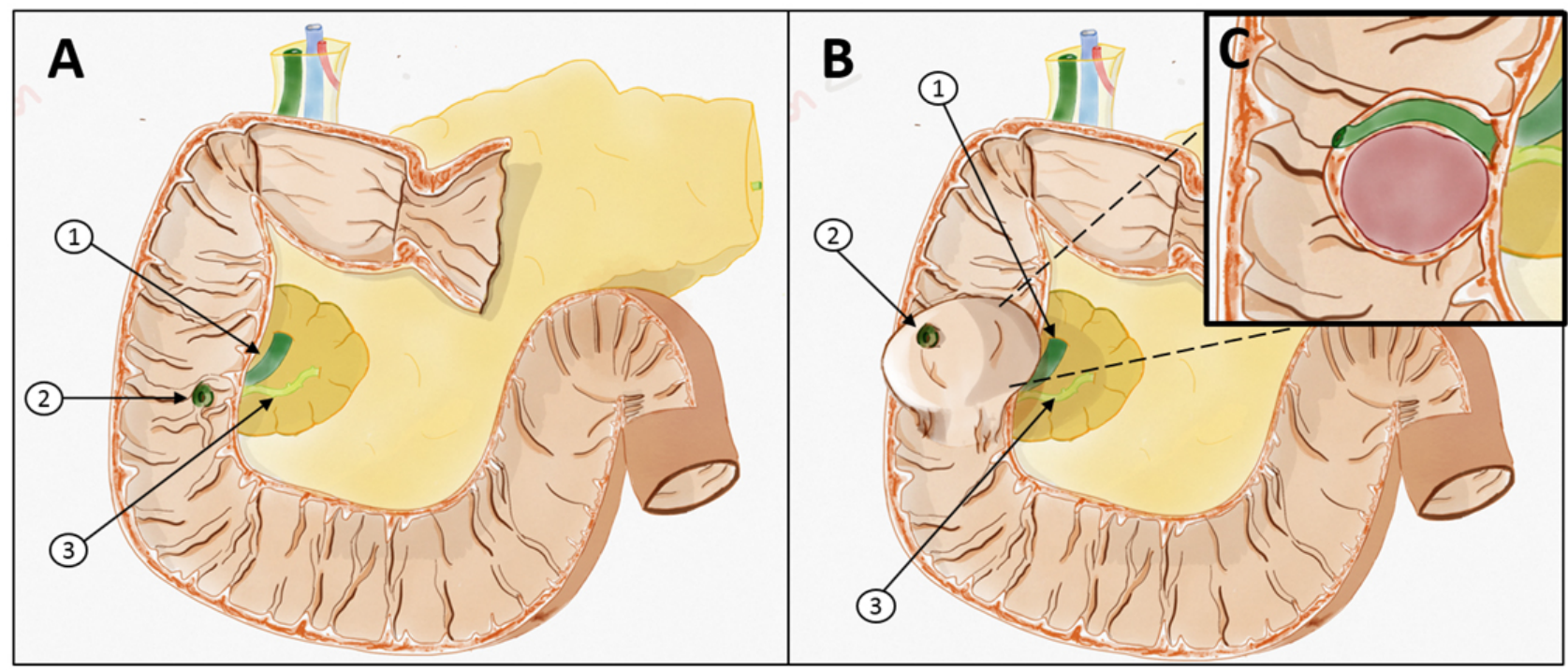

Figure 3. Schematic diagram of the DDC anatomy

Normal anatomy (A). Duodenal duplication cyst displacing the ampulla (B). Common bile duct (1), ampulla (2), pancreatic duct (3). Common bile duct running between the inner wall of the medial duodenum and the cyst wall $(C)$

Distinguishing between a DDC and a type III choledochal cyst preoperatively can be challenging, as has been previously reported. ${ }^{[10-12]}$ The clinical presentation may be similar in both: recurrent abdominal pain, vomiting and even acute pancreatitis when there is communication of the DDC with the CBD or if there is CBD compression by the cyst. Imaging features on ultrasound and CT scan can show a cystic structure in similar location in both. However, MRCP will show the $\mathrm{CC}$ communicating with the $\mathrm{CBD}$, whereas the DDC does not. In addition, the pancreaticobiliary junction is normal in DDC. ${ }^{[9]}$ Moreover, the cyst is present distal to the ampulla, protruding into the duodenal lumen. ${ }^{[8,9]}$ In our case the patient presented a bulging cyst that displaced the CBD and the ampulla laterally. Understanding the relationship between the cyst and the bile duct is essential to minimize the risk of intraoperative injury. Figure 3 shows the anatomic re- 
lationships between the ampulla, the CBD and the duodenal duplication cyst. It is important to remember that the CBD runs between the inner wall of the medial duodenum and the cyst wall. Therefore the ampulla and CBD are displaced by the cyst, so care must be taken not to injure the ampulla during the resection.

Malignancy has been reported in three cases of DDC, including two cases of adenocarcinoma and one carcinoid tumor. ${ }^{[13-15]}$ If incomplete resection (marsupialization or unroofing) is performed, surveillance should be considered, using periodic endoscopy and biopsies 6 to 12 months after the procedure. ${ }^{[9]}$ In patients with symptomatic CC, the incidence of malignant tumors has been estimated to be $2.5 \%$, including ampullary carcinoma and cholangiocarcinoma. ${ }^{[16,17]}$ The incidence of malignancy in CC appears to be lower than with other types of choledochal cysts. ${ }^{[18]}$

While the clinical presentation of DDC and CC share similarities, these two conditions have disparate embryologic origins. Etiologies of DDC formation remain unclear, but hypotheses include vascular injury, recanalization defects, split notochord, and partial twinning. ${ }^{[1]}$ Regarding choledochal cyst formation, abnormalities during early development of the hepatic diverticulum are thought to give rise to anomalous pancreaticobiliary union, ${ }^{[19]}$ which is defined as union of the pancreatic and biliary ducts outside of the duodenal wall. ${ }^{[20]}$

\section{REFERENCES}

[1] Jeziorczak PM, Warner BW. Enteric Duplication. Clin Colon Rectal Surg. 2018 Mar; 31(2): 127-131. PMid: 29487496. https: //doi.org/10.1055/s-0037-1609028

[2] Ladd WE, Gross RE. Surgical treatment of duplications of the alimentary tract enterogenous cysts, enteric cysts or ileum duplex. Surg Gynecol Obstet. 1940; 70: 295-307.

[3] Merrot T, Anastasescu R, Pankevych T, et al. Duodenal duplications. Clinical characteristics, embryological hypotheses, histological findings, treatment. Eur J Pediatr Surg. 2006; 16(01): 18-23. PMid: 16544221. https://doi.org/10.1055/s-2006-923798

[4] Macpherson RI. Gastrointestinal tractduplications : clinical, pathologic, etiologic, andradiologic considerations. Radiographics.1993; 13(05): 1063-1080. PMid: 8210590. https://doi.org/10.114 8/radiographics.13.5.8210590

[5] Sujka JA, Sobrino J, Benedict LA, et al. Enteric duplication in children. Pediatr Surg Int. 2018 Dec; 34(12): 13291332. PMid:30315502. https://doi.org/10.1007/s00383-0 $18-4362-\mathrm{x}$

[6] Guérin F, Podevin G, Petit T, et al. Outcome of alimentary tract duplications operated on by minimally invasive surgery: a retrospective multicenter study by the GECI (Groupe d'Etude en Coeliochirurgie Infantile). Surg Endosc. 2012 Oct; 26(10): 2848-55. PMid: 22538674. https://doi.org/10.1007/s00464-012-2259-7
This results in a long common channel, ${ }^{[21]}$ with a channel > $15 \mathrm{~mm}$ considered abnormal. ${ }^{[22]}$ However, pancreaticobiliary junction abnormalities are less common in choledochoceles, occurring in $<20 \%$ of patients. ${ }^{[17]}$

Although the macroscopic surgical findings may be similar, there is no continuum between type III choledocele and periampullary DDC. Definitive distinction between the two entities can be made histologically. DDC, like all enteric duplications, have a smooth muscle outer layer and an intestinal epithelial lining. ${ }^{[23]}$ DDCs often have two duodenal mucosal layers, each with their respective muscularis mucosae, separated by a layer of submucosa. ${ }^{[9]}$ In contrast, choledochal cysts contain a biliary mucosa. ${ }^{[24]}$

\section{ACKNOWLEDgements}

I would like to thank Dr. Goldstein for allowing me to work on his behalf during this year. Moreover, this adventure could not have been done without the indefectible support of my supervisor, Pr Poli-Merol, for whom I express my deepest respect. Finally, I would particularly like to thank the American committee of the Reims pediatric hospital for allowing my family and I to realize this great adventure and to help us to progress in our professional and personal fields.

\section{CONFLiCTS OF INTEREST Disclosure}

The authors declare they have no conflicts of interest.
[7] Karnak I, Ocal T, Senocak ME, et al. Alimentary tract duplications in children: report of 26 years' experience. Turk J Pediatr. 2000 Apr-Jun; 42(2): 118-25. Review.

[8] Wada S, Higashizawa T, Tamada K, et al. Endoscopic partial resection of a duodenal duplication cyst. Endoscopy. 2001 Sep; 33(9): 808-10 PMid: 11558037. https://doi.org/10.1055/s-2001-16528

[9] Antaki F, Tringali A, Deprez P, et al. A case series of symptomatic intraluminal duodenal duplication cysts: presentation, endoscopic therapy, and long-term outcome (with video). Gastrointest Endosc. 2008 Jan; 67(1): 163-8. PMid: 18155438. https://doi.org/10 $.1016 / \mathrm{j}$.gie. 2007.08 .006

[10] Koffie RM, Lee S, Perez-Atayde A, et al. Periampullary duodenal duplication cyst masquerading as a choledochocele. Pediatr Surg Int. 2012 Oct; 28(10): 1035-9. PMid: 22752148. https: //doi.org/10.1007/s00383-012-3116-4

[11] Lakhtakia S, Gupta R, Mateen MA, et al. Giant choledochocele presenting as intussusception (with video). Gastrointest Endosc. 2008 Dec; 68(6): 1194-5; discussion 1196. PMid: 18951129. https://doi.org/10.1016/j.gie.2008.05.058

[12] Guarise A, Faccioli N, Ferrari M, et al. Duodenal duplication cyst causing severe pancreatitis: imaging findings and pathological correlation. World J Gastroenterol. 2006 Mar 14; 12(10): 1630-3. PMid: 16570360. https://doi.org/10.3748/wjg.v12.i10.1630

[13] Falk GL, Young CJ, Parer J. Adenocarcinoma arising in a duodenal duplication cyst: a case report. The Australian and New 
Zealand Journal of Surgery. 1991; 61: 551-3. PMid: 1859319. https://doi.org/10.1111/j.1445-2197.1991.tb00289.x

[14] Hata H, Hiraoka N, Ojima H, et al. Carcinoid tumor arising in a duplication cyst of the duodenum. Pathology International. 2006; 56 272-8. PMid: 16669876. https://doi.org/10.1111/j.1440-1 $827.2006 .01957 . \mathrm{x}$

[15] Inoue M, Nishimura O, Andachi H, et al. Early cancer of duodenal duplication. A case report. Gastroenterologia Japonica. 1979; 14: 233-7. PMid: 447002. https : //doi.org/10.1007/BF02774072

[16] Ladas SD, Katsogridakis I, Tassios P, et al. Choledochocele, an overlooked diagnosis: report of 15 cases and review of 56 published reports from 1984 to 1992. Endoscopy. 1995; 27: 233-9. PMid: 7664701. https://doi.org/10.1055/s-2007-1005677

[17] Ziegler KM, Pitt HA, Zyromski NJ, et al. Choledochoceles: are they choledochal cysts? Annals of Surgery. 2010; 252: 683-90.

[18] Soreide K, Soreide JA. Bile duct cyst as precursor to biliary tract cancer. Annals of Surgical Oncology. 2007; 14: 1200-11. PMid 17187167. https://doi.org/10.1245/s10434-006-9294-3

[19] Li L, Yamataka A, Wang YX, et al. Anomalous pancreatic duct anatomy, ectopic distal location of the papilla of Vater and congenital biliary dilatation: a new developmental triad? Pediatr Surg Int. 2003 May; 19(3): 180-5.

[20] Ono S, Fumino S, Iwai N. Diagnosis and treatment of pancreaticobiliary maljunction in children. Surg Today. 2011 May; 41(5): 601-5. PMid: 21533929. https://doi .org/10.1007/s00595-0 10-4492-9

[21] Li L, Yamataka A, Yian-Xia W, et al. Ectopic distal location of the papilla of vater in congenital biliary dilatation: Implications for pathogenesis. J Pediatr Surg. 2001 Nov; 36(11): 1617-22. PMid: 11685686. https://doi.org/10.1053/jpsu.2001.27932

[22] Liu QY, Nguyen V. Endoscopic approach to the patient with congenital anomalies of the biliary tract. Gastrointest Endosc Clin N Am. 2013 Apr; 23(2): 505-18. PMid: 23540973. https://doi .org/10 $.1016 /$ j.giec. 2012.12.004

[23] Gross RE, Holcomb GW, Jr., Farber S. Duplications of the alimentary tract. Pediatrics. 1952; 9: 448-68.

[24] de Vries JS, de Vries S, Aronson DC, et al. Choledochal cysts: age of presentation, symptoms, and ate complications related to Todani's classification. J Pediatr Surg. 2002 Nov; 37(11): 1568-73. PMid: 12407541. https://doi.org/10.1053/jpsu. 2002.36186 